- ACORN Australan college of | JOURNAL OF PERIOPERATIVE NURSING

Volume 33 | Issue 1

Article 2

$3-1-2020$

\title{
Factor V Leiden and superior mesenteric artery occlusion: A case study
}

Follow this and additional works at: https://www.journal.acorn.org.au/jpn

Part of the Health Services Administration Commons, Health Services Research Commons, Perioperative, Operating Room and Surgical Nursing Commons, and the Surgery Commons

(c) (†)

This work is licensed under a Creative Commons Attribution 4.0 License.

\section{Recommended Citation}

Atayde, Cristina (2020) "Factor V Leiden and superior mesenteric artery occlusion: A case study," Journal of Perioperative Nursing: Vol. 33 : Iss. 1 , Article 2.

Available at: https://doi.org/10.26550/2209-1092.1074

https://www.journal.acorn.org.au/jpn/vol33/iss1/2

This Article is brought to you for free and open access by Journal of Perioperative Nursing. It has been accepted for inclusion in Journal of Perioperative Nursing by an authorized editor of Journal of Perioperative Nursing. 


\section{Guest Editor}

Paula Foran

PhD, MACN, FACORN

\section{Author}

Cristina Elena Atayde

BN, MCN (Acute Care Nursing), CNE, NSLHD

Cristina.atayde@health.nsw.gov.au

\title{
Factor V Leiden and superior mesenteric artery occlusion: A case study
}

\begin{abstract}
Factor $\mathrm{V}$ Leiden (FVL) is an inherited condition that prolongs the clotting process; this subsequently places individuals at a higher risk of developing a thromboembolism? This case study will discuss a 41-year-old female who developed a superior mesenteric artery occlusion with subsequent small bowel ischaemia on a background of FVL. The discussion will illustrate the rarity of an arterial occlusion, the risk factors that are associated with an ischaemic small bowel, the implications of inheriting FVL and some of the associated social aspects of an ileostomy.
\end{abstract}

\section{Background}

This case is important due to the rarity of an arterial occlusion, the risk factors that place an individual at higher risk of developing such a diagnosis and because it exposes some of the potential implications for a sufferer's quality of life. The prevalence of FVL is estimated to be 4-5 per cent of the general population; however, FVL only increases the chances of developing a venous thromboembolism if in conjunction with other associated risk factors ${ }^{2,3}$. This case study aims to contribute to the literature examining the correlation between FVL and an arterial occlusion².

\section{Case presentation}

Mrs Jane Hopkins (pseudonym) is a 40-year-old woman who presented to a regional hospital before being transferred to a large metropolitan hospital in Sydney after travelling to the United States for a holiday. While overseas, she was hospitalised with severe abdominal pain requiring a superior mesenteric artery (SMA) stent in her previously inserted superior mesenteric artery bypass graft. She was discharged from the United States hospital and had returned home to Sydney for one week before presenting to hospital with further episodic abdominal pain. During Jane's admission she was admitted in and out of the intensive care unit, was hospitalised for approximately three months and underwent numerous surgical procedures.
Her past medical history included type two diabetes mellitus (T2DM), peptic ulcer disease, depression and anxiety, hyperlipidaemia, factor $\mathrm{V}$ Leiden, two previous miscarriages of unknown cause, a left brachial artery thrombectomy in 2014, an aortic superior mesenteric artery bypass grafting and endarterectomy in 2015 for atherosclerosis and chronic abdominal angina, she is an ex-smoker and was previously on the contraceptive pill.

Her current medications consisted of aspirin $100 \mathrm{mg}$ daily, apixaban $5 \mathrm{mg}$ twice daily which was newly commenced in the United States post stent, simvastatin $80 \mathrm{mg}$ daily, omeprazole $20 \mathrm{mg}$ daily, metformin $500 \mathrm{mg}$ twice daily and she was prescribed ciprofloxacin and metronidazole antibiotic course that she recently finished after stenting. The doses for these latter 
medications that Jane was prescribed were not noted as they were prescribed overseas. She commenced Ibuprofen as a form of analgaesic, there was no documentation to note if this was suggested on discharge from the United States hospital or purchased over the counter. She has an allergy to amoxicillin and bee stings.

While in the regional hospital, Jane was sent for a computed tomography of abdomen and pelvis (CTAP) and a computed tomography mesenteric angiography (CTMA). Her lactate was not measured on arrival at hospital and her $C$ reactive protein (CRP) level was $34 \mathrm{mg} / \mathrm{L}$. The CTMA showed a patent SMA graft, so Jane was subsequently admitted under the colorectal team. While in the emergency department (ED) Jane developed tachycardia up to 128 beats per minute and was hypotensive with a blood pressure of $92 / 65$. Her abdominal pain was worsening and she was clinically deteriorating. Because of this Jane underwent an emergency laparotomy for a potential bowel resection for a suspected ischaemic bowel.

During the procedure there was no ischaemia found, but $30 \mathrm{~cm}$ of bowel was removed as it was adhering to the bladder, oedematous and significantly thickened with fat wrapping causing narrowing of the lumen. Incidentally a $10 \mathrm{~cm}$ left-sided ovarian cyst was noted and removed by a consulting gynaecologist. She was commenced on a heparin infusion while off the apixaban.

Jane was kept nil by mouth with intravenous (IV) therapy, had a Salem sump nasogastric tube (NGT) in place and was closely monitored postoperatively. On post-operative day four, Jane's pain worsened and she had persistently high NGT output, greater than $1.5 \mathrm{~L}$ per day. Her CRP level was $425 \mathrm{mg} / \mathrm{L}$ and rising, she was persistently nauseated and when trialled on sips of clear fluid she would dry retch. In order to investigate this deterioration, a CTAP was re-ordered. The results indicated further ischaemia. The vascular team was consulted for their input and a triple phase computed tomography (3PCT) was ordered. The 3PCT confirmed the SMA stent was providing a reduced blood supply; however, there was adequate collateral blood flow. She was showing signs of improvement by this stage with reduced output from her NGT, reduced nausea, improving CRP and a lactate of $1.0 \mathrm{mmol} / \mathrm{L}$. Because Jane remained otherwise clinically stable and improving, she was commenced on total parenteral nutrition (TPN) day six postoperatively and monitored closely for any further signs of deterioration.

By day nine her NGT was removed, as her NGT output was less than $300 \mathrm{ml}$ per day. She was commenced on a full fluid diet, was haemodynamically stable and feeling much improved. The vascular team were still frequently consulting Jane and ordered a repeat 3PCT as a followup scan. The 3PCT diagnosed an anastomotic leak and the vascular team remained confident that there was adequate collateral flow to supply the small bowel. A family meeting was held with discussion about an ileostomy for the anastomotic leak instead of a drain insertion in interventional radiology due to the risk of a fistula or further complications.

On day 12 post-operatively Jane returned to theatre for an exploratory laparotomy. There was free fluid intra-abdominally which was both purulent and haemoserrous. It was found that $50 \mathrm{~cm}$ of ileum was ischaemic and subsequently resected, which meant that a total of $80 \mathrm{~cm}$ of small bowel had been removed. The superior mesenteric artery was unable to be visualised so it was decided that the abdomen be left open with negative pressure wound therapy (NPWT) applied at $-80 \mathrm{mmHg}$.

On day 14 after the initial operation Jane went for a 'second look' laparotomy. An estimated $70 \mathrm{~cm}$ of bowel appeared dusky but not ischaemic; no bowel was resected and it was decided that the vascular team would investigate intraoperatively later that afternoon. She returned to theatre and the vascular team stated that her saphenous vessel was not ideal for grafting and the use of a prosthetic graft would likely cause an infection because of the current condition of the bowel. After numerous attempts to flush the superior mesenteric artery, a stent was placed and an intra-operative angiography was performed which showed excellent flow. Additionally, glyceryl trinitrate was used on the small bowel vessels in an attempt to improve blood flow with vasodilation ${ }^{4}$. Jane's abdomen was again left open and NPWT was applied at $-50 \mathrm{mmHg}$. On post-operative day 16, Jane went back to theatre for an ileostomy formation and abdominal closure. A further $15 \mathrm{~cm}$ of bowel was resected (now $95 \mathrm{~cm}$ in total) due to ischaemia, a loop ileostomy was performed, and her abdomen was closed.

Throughout Jane's recovery her ileostomy output remained high despite the use of antidiarrheal and antimotility agents. This was due to short bowel syndrome. She was unable to absorb many of her oral medications as they were being expelled whole due to the shortened length of bowel and subsequent faster transit time ${ }^{5,6}$. Because of this, the haematology team ceased the IV heparin and she was commenced on a twice-daily dose of therapeutic clexane for the treatment of her FVL. The implications of an ileostomy can dramatically affect one's quality of life. Jane was also managing 
an acute illness with subsequent ICU admissions and a long-term admission into a large metropolitan hospital that was one hour away from her home and family. She required a mental health referral and was diagnosed with major depressive disorder.

Jane has a history of hyperlipidaemia which worsened when commenced on TPN. Her TPN formula and administration regime was altered and she was commenced on fenofibrate as well as her regular simvastatin. This is discussed in more depth later in this case study.

Throughout her procedures anatomical pathology was routinely sent off for investigations. It was later discovered that the initial ischaemia was potentially caused by a hydrophilic polymer emboli, thought to have been from the superior mesenteric artery graft stent placed in the United States. Jane received a bill for AU\$115 000, which her travel insurance company refused to pay as they stated the medical issues were caused from a prior condition. This is also discussed in more depth later in this study.

\section{Differential diagnosis}

Jane was taking ibuprofen as her analgesic despite her history of peptic ulcer disease. Because of this there was a possibility of gastritis or a potential bleeding peptic ulcer. A patient presenting with this will usually present with epigastric pain that is less severe than that of an ischaemic bowel'. If they are actively bleeding, they will present with haematemesis or melena and will have reduced levels of haemoglobin ${ }^{8}$.

Jane also presented with a history of persistent loose stools since commencing antibiotics. A stool sample was sent to screen for Clostridium difficile. Antibiotic use is a risk factor for obtaining Clostridium difficile and Jane was on clindamycin?. The use of proton pump inhibitors also present with a correlation to Clostridium difficile and she had been on regular omperazole?. She presented with common signs and symptoms including diarrhoea, nausea and abdominal pain. However, her CT abdomen was not consistent with such a presentation and her previous history was more indicative of ischaemic pathology.

\section{Investigations}

Jane has known risk factors and a correlating medical history consistent with an ischaemic bowel. The investigations in Table 1 (below) were completed to diagnose this.

\section{Treatment}

Jane underwent complex surgical and pharmacological treatment as described in Table 2 on the following page and in further depth in the discussion.

\section{Outcome and follow-up}

A reversal of Jane's ileostomy is planned. After approximately three to six months, once her anastomosis is believed to have adequately rested and repaired and she is in optimum health, Jane will have an elective ileostomy reversal. The stoma will be freed from the abdominal wall and anastomosed to the remaining colon ${ }^{14}$. Once the ileostomy is reversed, Jane will no longer require TPN as her short bowel syndrome will likely resolve as the reconnection of her small bowel to her colon will reduce transit time. If all goes well, Jane will be able to

\section{Table 1: Diagnostic investigations}

\begin{tabular}{|c|c|}
\hline $\begin{array}{l}\text { CTAP } \\
\text { (computed tomography } \\
\text { of abdomen and pelvis) }\end{array}$ & $\begin{array}{l}\text { This can provide an in depth understanding of the bowel and the extent of bowel } \\
\text { compromise. This is usually performed prior to a CTMA as it will provide an indication of } \\
\text { bowel ischaemia }{ }^{10} \text {. }\end{array}$ \\
\hline $\begin{array}{l}\text { CTMA } \\
\text { (computed tomography } \\
\text { mesenteric } \\
\text { angiography) }\end{array}$ & $\begin{array}{l}\text { A definitive diagnosis of an occlusion understandably relies upon demonstration of an } \\
\text { occlusion in imaging. A CTMA is performed when there is the intention for an endovascular } \\
\text { intervention. A contrast solution is injected and a total occlusion will show no filling of the } \\
\text { arteries while a partial occlusion will show vasoconstriction }{ }^{10} \text {. }\end{array}$ \\
\hline $\begin{array}{l}\text { 3РCT } \\
\text { (triple phase computed } \\
\text { tomography) }\end{array}$ & $\begin{array}{l}\text { This scan provides a greater understanding of blood flow and organ conditions as it is } \\
\text { performed in three phases: unenhanced, arterial and portal venous }{ }^{11} \text {. }\end{array}$ \\
\hline Lactate & $\begin{array}{l}\text { A normal lactate concentration is } 0.5-1.5 \mathrm{mmol} / \mathrm{L} 12 \text {. The lactate level elevates when there } \\
\text { is impaired tissue oxygenation to cells. Therefore, if ischaemia is evident an elevated } \\
\text { lactate level can be expected. However, an elevated lactate level is deemed a relatively } \\
\text { late sign in the course of the development of an ischaemic bowel. }\end{array}$ \\
\hline $\begin{array}{l}\text { CRP } \\
\text { (C reactive protein) }\end{array}$ & $\begin{array}{l}\text { Elevated levels of CRP indicate an acute or chronic inflammation within the body. A normal } \\
\text { CRP level is below } 3.0 \mathrm{mg} / \mathrm{L}^{13} \text {. }\end{array}$ \\
\hline
\end{tabular}


Table 2: Treatment

\begin{tabular}{|l|l|}
\hline Exploratory laparotomy & $\begin{array}{l}\text { A suspected ischaemic event, perforation or peritonitis warrants an emergency exploratory } \\
\text { laparotomy?. Jane went to theatre as she began to deteriorate while in the emergency } \\
\text { department and the suspected diagnosis was consistent with her medical history. }\end{array}$ \\
\hline Anticoagulation & $\begin{array}{l}\text { Once diagnosed with an SMA occlusion a patient will be managed on an IV heparin } \\
\text { infusion and their therapeutic range will be titrated based on their activated partial } \\
\text { thromboplastin time (APTT) }\end{array}$ \\
\hline $\begin{array}{l}\text { Repeat exploratory } \\
\text { laparotomy }\end{array}$ & $\begin{array}{l}\text { Jane had a 3PCT and an anastomotic leak was noted. She returned to theatre and a bowel } \\
\text { resection was performed for ischaemic bowel. Her abdomen was then left open as a } \\
\text { second look laparotomy was indicated. }\end{array}$ \\
\hline $\begin{array}{l}\text { Stent insertion in } \\
\text { bypass graft }\end{array}$ & $\begin{array}{l}\text { Jane previously had a bypass graft in } 2015 \text { for atherosclerosis that was causing chronic } \\
\text { abdominal angina due to a reduced blood supply. Her SMA bypass managed to be re- } \\
\text { stented and her bowel was again left open for a second look laparotomy. }\end{array}$ \\
\hline Ileostomy formation & $\begin{array}{l}\text { Jane had an ileostomy formed in order to protect her anastomosis }{ }^{14} \text {. It will eventually be } \\
\text { reversed after her anastomosis has time to repair. }\end{array}$ \\
\hline
\end{tabular}

re-commence oral apixaban and will no longer require twice daily clexane. Jane will require ongoing support from the mental health team in the community; however, once her quality of life has improved there is hope that her requirements for antidepressants will reduce and hopefully cease.

\section{Discussion}

FVL is a blood disorder that is an inherited genetic mutation. The mutation can be present in one chromosome or both to form a pair suggesting it can be passed on from one parent or both parents to their children?. A person is heterozygous for FVL if they inherited the mutation from one parent, homozygous if they inherited it from both parents. In Jane's case she was diagnosed as heterozygous for FVL. Factor $V$ is required to allow for clotting to occur in the body as a natural response to injury. Fibrin will grasp platelets to the site of injury to form a clot ${ }^{3}$. Factor $V$ aids with the release of fibrin and when enough has been released, protein $\mathrm{C}$ is released to inactivate factor $V$. However, in FVL factor $V$ is resistant to protein
C causing the clotting process to continue on for a prolonged period of time $e^{1,3}$.

Hydrophilic polymer is a type of synthetic material used as the coating on vascular devices such as stents, sheaths and guide wires $^{15}$. Hydrophilic polymer has unique properties that improve biocompatibility while reducing friction between vessel walls and devices ${ }^{15,16}$. However, in more recent years, hydrophilic polymer emboli have been identified as a potentially fatal iatrogenic complication ${ }^{16}$. A study in 2018 found that a large number of hydrophilic polymer emboli have been reported from the United States consistent with Jane's case. FVL causing an SMA occlusion is deemed relatively uncommon ${ }^{17}$. However, other studies suggest the only mutations proven to cause an arterial occlusion in patients less than 55 years old are FVL mutation, protein $\mathrm{C}$ and protein $\mathrm{S}$ deficiencies ${ }^{18,19,20}$. Mortality rates of a complete occlusion are 77-93 per cent ${ }^{17}$. Consequently, patients should be managed in an intensive care setting with a multidisciplinary team approach $^{17,21}$. The multidisciplinary teams should include haematology, vascular, surgical and possibly psychiatric involvement; this was evident in Jane's case. Best practice for the investigation of a possible SMA thrombus is a CTMA, which was also completed during Jane's admission ${ }^{21}$. Other management strategies are dependent upon the extent of ischaemia ${ }^{21}$. A second look laparotomy, intravenous heparin in the acute phase, progression to oral anticoagulants when absorbency is established, and vascular management is dependent upon the vessel damage ${ }^{21}$. Interventions include fibrinolysis, angioplasty, embolectomy, stenting and bypass grafting ${ }^{2}$. A previously reported case with a 32-year-old patient highlights the rarity of the condition, imaging difficulties and the importance of obtaining a reliable history ${ }^{21,22}$. Interestingly, studies suggest that being diagnosed with FVL alone does not predispose an individual to an occlusion except if they have other risk factors. In Jane's case, she was previously on the contraceptive pill and is an ex-smoker with an SMA 
bypass graft and these are strong risk factors of the condition.

The principal indicator for an open abdomen is a second look laparotomy; other indicators include vascular injuries, swelling and the risk of abdominal compartment syndrome ${ }^{23}$. Optimisation of the patient's haemodynamic condition between operations can lead to potentially salvaging bowel that once potentially appeared ischaemic $\mathrm{c}^{23,24}$. The current gold standard for management of an open abdomen is NPWT at a minimum negative pressure; however, there is discussion around this causing bowel damage and further anastomotic complications ${ }^{24,25}$. Conversely, a retrospective study concluded that non-open abdomen patients after SMA occlusion more frequently required a further bowel resection at the second look, subsequent short bowel syndrome and a higher incidence of sepsis $^{24}$.

Short bowel syndrome, also commonly known as intestinal failure, ensues when an extensive amount of small bowel is resected leading to an inadequate amount remaining to absorb and manage the patient's nutritional and hydration requirements ${ }^{5,6}$. The lessened surface area of the bowel reduces the interaction time of nutrients with intestinal villi and the shortened length of bowel subsequently causes a faster transit time ${ }^{5}$. Short bowel syndrome does not always occur after resection. It is dependent on the extent to which the bowel adapts its functioning through morphologic and functional changes and which part of the bowel is resected ${ }^{26}$. The primary therapy for short bowel syndrome is TPN ${ }^{5}$. Often TPN can be weaned once intestinal adaption begins or, in Jane's case, after her ileostomy is reversed ${ }^{27}$. Being discharged on TPN has a number of impacts on a patient's personal life. The patient will have to understand how to use their central venous access device and how to use an IV pump, attend frequent medical appointments, change their eating habits, maintain a strict fluid balance chart, manage continuous surveillance of medical issues and know when to seek medical advice ${ }^{28}$. Jane had a Hickman catheter inserted to manage her TPN, her social life will be affected due to TPN administration times, and she is facing physical appearance and self-confidence issues. Jane has ongoing care from the mental health team due to her history of anxiety and depression and has been commenced on antidepressant medications.

Lipids are vital for numerous physiological functions at a cellular level. They regulate permeability of cells, contribute to cell membrane integrity and aid pathways of the immune system ${ }^{29}$. However, when there are too many circulating lipids, conditions known as hypercholesterolaemia and hypertriglyceridaemia are risk factors for cardiovascular disease and TPN increases the risks of such complications ${ }^{29,30}$. In a healthy adult, lipids are broken down by lipoprotein lipase (LPL) to be used as energy, metabolised as required or stored for future use. An ill individual's LPL release is reduced and subsequently lipids continue to build in the blood ${ }^{29}$. Such build-up of lipids may further advance Jane's atherosclerosis and potentially occlude her recently restented SMA bypass graft. To manage this, Jane's cyclic TPN was changed back to a 24-hour-a-day regime, she was commenced on fenofibrate $145 \mathrm{mg}$ daily in conjunction with her regular simvastatin and her fluid balance was strictly managed.

\section{Implications for practice}

Jane was initially on aspirin 100 mg daily after her SMA bypass graft in 2015. She was managed with yearly ultrasounds. Studies support the use of long-term oral anticoagulants in conjunction with a statin or at a minimum an antiplatelet agent ${ }^{10}$. Lifestyle factors should also be evaluated as they can also significantly contribute to cardiovascular health?. However, being diagnosed with FVL alone does not indicate the use of an anticoagulant 3,10 though when exposed to other potential risk factors such as surgical interventions then anticoagulation should be considered $^{10}$.

There is little information about long-haul air travel and FVL, though regular leg exercises, the use of compression stockings and maintaining hydration is said to be an adequate prevention strategy if the patient has no significant medical history ${ }^{3}$. However, Jane's history included a bypass graft and studies support adequate longterm anticoagulation similar to the treatment of atrial fibrillation ${ }^{10}$. Jane will have to be discharged on prolonged clexane due to her short bowel syndrome leading to an inability to absorb oral anticoagulants $^{10}$. She will also require duplex ultrasounds three months after stenting, six monthly following that for two years, then yearly for the remainder of her life $\mathrm{l}^{31}$.

To manage Jane's short bowel syndrome a strict, self-managed fluid balance chart will need to be maintained to control her risk of dehydration ${ }^{5}$. When rehydrating with IV therapy it is essential to monitor Jane's electrolytes as potassium and magnesium can be easily lost via the ileostomy as the small bowel re-absorbs fluids ${ }^{5,31}$. Jane was encouraged to sip on an oral electrolyte drink throughout the day. Other factors were also used in an attempt to reduce Jane's fluid loss. Antidiarrhoeals and 
antimotility agents such as psyllium husk, loperamide, codeine, lomotil and octreotide were used to reduce gastric motility and subsequently to prolong transit time ${ }^{6,31}$. Jane was also already on a proton pump inhibitor; however this was changed to IV pantoprazole $40 \mathrm{mg}$ twice a day to prevent overgrowth of gut bacteria ${ }^{31}$. Patients with short bowel syndrome are at risk of multiple micronutrient deficiencies, including vitamin B12, other vitamins and electrolytes; therefore, daily blood tests are needed to closely monitor, evaluate and manage micronutrient levels. The TPN Clinical Nurse Consultant (CNC) plays a significant role in managing such deficiencies. This nurse also plays an important role in educating Jane and preparing her to care for her Hickman catheter at home, connect and disconnect from TPN as well as linking her up with government funding to support her once she is discharged.

Although Jane's ileostomy is only short term, it will still have detrimental effects on her quality of life. It will change the way she completes everyday activities - she will have to manage wearing a stoma bag under her clothes; manage complications such as leaks, bag changes and skin irritation; change her diet and manage her social, sexual and emotional functioning ${ }^{32}$. Jane has a supportive long-term partner who has taken time off work to assist her in managing practical skills with her stoma care, TPN management and to support her emotionally. Despite this, Jane may still encounter issues with self-image and confidence. Jane was referred to the mental health team who frequently consult with her and her family as required. She was commenced on fluoxetine 10 mg daily after being diagnosed with major depressive disorder. The fluoxetine was later increased to
$20 \mathrm{mg}$ daily; this is consumed after dissolving the tablets in water to optimise absorption. The social work department has been heavily involved with supporting her with the appropriate paperwork and legal aid to challenge the insurance company's decision not to pay the medical bills from the United States. The hospital social worker is also involved in liaising with her employer who is holding her job for her while she is on sick leave from work.

\section{Statement}

This case study follows and abides by the Australian National Health and Medical Research Council's definition of quality assurance. The purpose of this case study was to improve the quality of care provided by health care professionals by gaining a deeper understanding of the conditions discussed. The case study involved minimal risks and inconvenience to the participant whom signed a written consent. All data collected has been de-identified and the age, gender and country of travel has been slightly altered for confidentiality purposes.

\section{Acknowledgements}

This paper was submitted to the University of Tasmania for assessment item three for the subject CNA803 Advanced Clinical Nursing Practice for the Master of Clinical Nursing. I would like to acknowledge the course coordinator, Paula Foran, and the marking team for their support and guidance throughout the course and during the submission of this paper.

\section{References}

1. Applegate J, Gronefeld D. Factor V Leiden. Radiol Technol 2019;90(3):259-273.

2. Hadiatou B, Ali G, David G. Acute mesenteric ischemia in an African American with heterozygous Factor $V$ Leiden deficiency. J Community Hosp Intern Med Perspect 2019;9(3):255-257.
3. Bauer K. Factor V Leiden and activated protein C resistance [internet]. UpToDate; 2019 [cited 2019 October 4]. Available from: www.uptodate.com/contents/factor-vleiden-and-activated-protein-c-resistance.

4. Cleveland TJ, Nawaz S, Gaines PA. Mesenteric arterial ischemia: Diagnosis and therapeutic options. Vasc Med 2002;7:311-321.

5. Biliauws L, Maggiori L, Joly F, Panis Y. Medical and surgical management of short bowel syndrome. J Visc Surg2018;155(4):283-291.

6. Biliauws L, Joly F. Emerging treatments for short bowel syndrome in adult patients. Expert Rev Gastroenterol Hepatol 2019;13(3):241-246.

7. Roon AV, Lewis J. Ischaemic bowel disease [Internet]. BMJ; 2019 [cited 2019 October 8]. Available from: bestpractice.bmj. com.acs.hcn.com.au/topics/en-gb/818/ prevention\#referencePop9.

8. Lynch KL. Peptic ulcer disease [Internet]. BMJ; 2019 [cited 2019 October 8]. Available from: bestpractice.bmj.com.acs.hcn.com.au/ topics/en-gb/80/pdf/80.pdf

9. Hassoun A. Clostridium difficile associated disease. BMJ 2018;363:k4369. doi: 10.1136/bmj. k4369.

10. Pearl G, Gilani R. Acute mesenteric arterial occlusion [Internet]. UpToDate; 2018 [cited 2019 October 7]. Available from: www. uptodate.com/contents/acute-mesentericarterial-occlusion

11. Waszczuk L, Guzinski M, Garcarek J, Sasiadek M. Triple-phase abdomen and pelvis computed tomography: Standard unenchanced phase can be replaced with reduced-dose scan. Pol J Radiol 2018;83:166170.

12. Emmett M, Szerlip H. Causes of lactic acidosis [Internet]. UpToDate; 2017 [cited 2019 October 9]. Available from: www.uptodate.com/contents/causes-oflactic-acidosis/print.

13. Kushner I. Acute phase reactants [Internet] UpToDate; 2019 [cited 2019 October 10]. Available from: www.uptodate.com/ contents/acute-phase-reactants.

14. Francone T. Overview of surgical ostomy for faecal diversion [Internet]. UpToDate; 2019 [cited 2019 October 10]. Available from: www.uptodate.com/contents/overview-ofsurgical-ostomy-for-fecal-diversion.

15. Mehta R, Mehta R. Hydrophilic polymer embolism: An update for physicians 2017;130(7):287-290.

16. Miyaoka M, Hatanaka K, Uekusa T, Nakamura N. Clinicopathological features of hydrophilic polymer emboli in Japanese autopsy cases. APMIS 2018;126(11):838-841. 
17. Acosta S, Ogren M, Sternby N, Bergqvist $D$, Bjork W. Incidence of acute thromboembolic occlusion of the superior mesenteric artery - a populationbased study. Eur J Vasc Endovasc Surg 2004;27(2):145-150.

18. Baburaj K, Salma Hanam A. Incidence of mesenteric arterial thrombosis in protein $\mathrm{S}$ deficiency patients. IAIM Journal 2015;2(11):74-77.

19. Mahmoodi BK, Brouwer JL, Veeger NJ, Van Der Meer J. Hereditary deficiency of protein C or protein S confers increased risk of arterial thromboembolic events at a young age: Results from a large family cohort study. Circulation 2008;118(16):1659-1667.

20. Mandegar MH, Saidi B, Roshanali F. Extensive arterial thrombosis in a patient with Factor V Leiden mutation. Interact Cardiovasc Thorac Surg 2010;11(1):127-129.

21. Scally N, O'Donnell M, McClintock C, Allen M, Kirk S, Dolan S. Mesenteric artery occlusion secondary to activated protein $C$ resistance: A life-threatening combination. Angiology 2008;58(6):768-771.
22. Dorweiler B, Neufang A, Kasper-Koenig W, Schinzel $H$, Schmiedt W, Oelert $H$. Arterial embolism to the upper extremity in a patient with Factor $V$ Leiden mutation (APC resistance): A case report and review of the literature. Angiology 2003;54(1):125-130.

23. Hansraj N, Pasley AM, Pasley JD, Harris DG, Diaz JJ, Bruns BR. Second-look laparotomy: Warranted, or contributor to excessive open abdomens? Eur J Trauma Emerg Surg 2019;45(4):705-711.

24. Wang Y, Alnumay A, Paradis T, Beckett A, Fata P, Khwaja K et al. Management of open abdomen after trauma laparotomy: A comparative analysis of dynamic fascial traction and negative pressure wound therapy systems. World J Surg 2019;10:1-7.

25. Acosta A, Karkkainen J. Open abdomen in acute mesenteric ischaemia. Anaesthesiol Intensive Ther 2019;51(2):159-162.

26. Cisler J, Buchman A. Intestinal adaption in short bowel syndrome. J Investigat Med 2015;53(8).

27. Sun $H$, Eliasson J, Fuglsang KA, Hvistendahl M, Naimia RM, Jeppesen PB. Repeated metabolic balance studies in patients with short bowel syndrome. JPEN 2019;9.
28. Huisman-de Waal G, Schoonhoven L, Jansen J, Wanten G, Achterberg T. The impact of home parenteral nutrition on daily life - A review. Clin Nutr 2007;25(3):275-288.

29. Raman M, Almutairdi A, Mulesa L, Alberda C, Beattie C, Gramlich L. Parenteral nutrition and lipids. Nutrients 2017;9(4):388.

30. Beton O, Ilundain G, Altemir T, Agundo $\mathrm{T}$, Gimeno O. Predictive factors of hypertriglyceridemia in in-hospital patients during total parenteral nutrition. Nutr Hosp 2017;34(3):505-511.

31. DiBaise JK. Management of the short bowel syndrome in adults [Internet]. UpToDate; 2018 [cited 2019 October 7]. Available from: www.uptodate.com/contents/managementof-the-short-bowel-syndrome-in-adults.

32. Haggstrom DA, Cheung WY. Approach to the long-term survivor of colorectal cancer [Internet]. UpToDate. 2019 [updated June 2019; cited 2019 October 7]. Available from: www.uptodate.com/contents/approachto-the-long-term-survivor-of-colorectalcancer/print 